\title{
Migration and HIV Risk Among Men Who Have Sex With Men, San Francisco, 2011.
}

\section{Citation}

Lama, Tenzing TS. 2018. Migration and HIV Risk Among Men Who Have Sex With Men, San Francisco, 2011.. Doctoral dissertation, Harvard Medical School.

\section{Permanent link}

http://nrs.harvard.edu/urn-3:HUL.InstRepos:41973478

\section{Terms of Use}

This article was downloaded from Harvard University's DASH repository, and is made available under the terms and conditions applicable to Other Posted Material, as set forth at http:// nrs.harvard.edu/urn-3:HUL.InstRepos:dash.current.terms-of-use\#LAA

\section{Share Your Story}

The Harvard community has made this article openly available.

Please share how this access benefits you. Submit a story. 
Scholarly Report submitted in partial fulfillment of the MD Degree at Harvard Medical School

Date: 20 September 2017

Student Name: Tenzing Lama AB, MSc (Res)

Scholarly Report Title: Migration and HIV Risk Among Men Who Have Sex With Men, San Francisco, 2011.

Mentor Name(s) and Affiliations: May Sudhinaraset, $\mathrm{PhD}$, Department of Epidemiology and Biostatistics, University of California, San Francisco; Willi McFarland, MD, PhD, Director of the Center for Public Health Research at San Francisco Department of Public Health \& Department of Epidemiology and Biostatistics, University of California, San Francisco; Henry Raymond, DrPH, San Francisco Department of Public Health \& Department of Epidemiology and Biostatistics, University of California, San Francisco. 


\section{$\underline{\text { Abstract }}$}

\section{Migration and HIV Risk Among Men Who Have Sex With Men, San Francisco, 2011.}

Tenzing Lama, May Sudhinaraset, Willi McFarland, Henry Raymond

In San Francisco, MSM account for nearly 90\% of HIV infections. Studies have postulated increased risk for HIV faced by MSM who migrate, particularly to urban environments, yet empirical data are lacking. In this study we analyzed data from the National HIV Behavioral Surveillance System collected in 2011 to ascertain whether nativity (U.S. versus foreign born) was associated with HIV prevalence, risk behavior, and service use. Among 510 MSM enrolled, HIV prevalence was $23.0 \%$. Multivariable analyses demonstrate that while nativity was not associated with increased risk for HIV infection, those who had lived in San Francisco for more than five years had higher HIV prevalence compared to those who had lived for less than a year even after adjusting for age, race, income, education, and location of birth. 


\section{$\underline{\text { Contributions }}$}

I co-designed the study with my mentors (MS, WM, HR).

I independently executed and analyzed the data. Mentors offered feedback.

I independently researched and wrote the paper. Mentors offered feedback.

HR submitted the paper to AIDS Education and Prevention.

\section{$\underline{\text { Publication Link }}$}

http://guilfordjournals.com.ezp-prod1.hul.harvard.edu/doi/abs/10.1521/aeap.2015.27.6.538

Lama TT, Sudhinaraset M, McFarland W, Raymond HF. Migration and HIV risk among men who have sex with men, San Francisco, 2011. AIDS Educ Prev. 2015; 27(6): 538-46. 
Appendix 1: The Published Manuscript 


\title{
MIGRATION AND HIV RISK AMONG MEN WHO HAVE SEX WITH MEN, SAN FRANCISCO, 2011
}

\author{
T. T. Lama, M. Sudhinaraset, W. McFarland, and H. F. Raymond
}

\begin{abstract}
In San Francisco, MSM account for nearly $90 \%$ of HIV infections. Studies have postulated increased risk for HIV faced by MSM who migrate, particularly to urban environments, yet empirical data are lacking. In this study we analyzed data from the National HIV Behavioral Surveillance System collected in 2011 to ascertain whether nativity (U.S. versus foreign born) was associated with HIV prevalence, risk behavior, and service use. Among 510 MSM enrolled, HIV prevalence was $23.0 \%$. Multivariable analyses demonstrate that while nativity was not associated with increased risk for HIV infection, those who had lived in San Francisco for more than five years had higher HIV prevalence compared to those who had lived for less than a year even after adjusting for age, race, income, education, and location of birth.
\end{abstract}

Migration, broadly defined as changing one's place of residence for time-limited stays or permanent settlement, and crossing a geographically defined border, has been correlated with HIV acquisition in many contexts of the epidemic (Decosas \& Adrien, 1997; Kane et al., 1993; Nunn, Wagner, Kamali, Kengeya-Kayondo, \& Mulder, 1995). Migration-related structural factors such as poverty, limited education, and cultural or linguistic barriers to health care services have been hypothesized to have the potential to increase the likelihood of HIV infection (Ayala, Bingham, Kim, Wheeler, \& Millett, 2012; Sanchez et al., 2004). However, migration's role in HIV risk for men who have sex with men (MSM) is under-studied.

Socio-structural factors in sending communities such as lack of jobs or educational opportunities are common reasons for migration. However, for MSM, migration can also be motivated by sexuality (Carrillo, 2004). Some MSM migrate to urban areas to escape familial or societal discrimination, social isolation, greater access to potential sexual partners, wider avenues for sexual expression, or sense of community (Bianchi et al., 2007; Chng, Wong, Park, Edberg, \& Lai, 2003; Huang \& Akhtar, 2005).

T. T. Lama, MSc, is affiliated with Harvard Medical School, Boston, Massachusetts. Sudhinaraset, PhD, W. McFarland, MD, PhD, and H. F. Raymond, DrPH, are affiliated with University of California, San Francisco. W. McFarland, MD, PhD, and H. F. Raymond, DrPH, are affiliated with the Center for Public Health Research, San Francisco Department of Public Health.

Address correspondence to H. Fisher Raymond, 25 Van Ness Ave., Suite 500, San Francisco, CA 94102.

E-mail: hfisherraymond@yahoo.com 
However, the sexuality of a migrant is not necessarily a risk indicator for HIV infection because sexual behavior and risk are multifactorial and complex involving a confluence of social, cultural, and personality variables (Jarama, Kennamer, Poppen, Hendricks, \& Bradford, 2005; Kalichman, Weinhardt, DiFonzo, Austin, \& Luke, 2002; Tsui \& Lau, 2010). Nonetheless, theoretical models exist that hypothesize that MSM migrants may be at increased vulnerability to high-risk sexual behaviors and HIV infection (Egan et al., 2011; Frye et al., 2006). MSM migrants may engage in high-risk sexual behaviors as a coping mechanism to deal with the alienating aspects of migration, fewer social constraints on behavior, greater anonymity, or precarious circumstances leading to exchange of sexual favors for food or money (Ayala et al., 2012; Díaz, Ayala, \& Bein, 2004; Sanchez et al., 2004).

Additionally, popular media portrayal of gay epicenters such as San Francisco and New York may also affect sexual behaviors and risk (Chauncey, 1994). While little on this matter has been studied, a qualitative study of Latino MSM migrants in New York City found that images of gay life in the U.S. was one of the drivers for migration and that the period immediately following migration was a particularly vulnerable time for engaging in risky behavior and contracting HIV (Bianchi et al., 2007; Oster et al., 2013). This study also found that new Latino MSM immigrants without enough money to go to commercial enterprises to meet sexual partners and those with limited English proficiency frequented public sex venues. Thus, socioeconomic status and linguistic ability to some extent affected the sexual risks of these immigrants (Bianchi et al., 2007).

There is limited empirical evidence of HIV prevalence, risk behavior, and other health factors for the MSM migrant population especially in a gay urban center such as San Francisco. The metropolitan San Francisco area is a well-known migration destination for MSM, with the highest percentage of reported same-sex households in the nation (Smith \& Gates, 2001). San Francisco also has one of the highest prevalence of HIV among MSM at 23\% (Raymond et al., 2013) and the largest proportion of the epidemic among MSM at about $90 \%$ of new HIV infections (San Francisco Department of Public Health, 2011). As such, migration to San Francisco may pose a higher risk of HIV acquisition among migrant MSM. Finally, the healthy migrant effect suggests that while migrants are healthier when they first arrive in a new country, cumulative stress and exposure to unhealthy factors may increase the risk of health behaviors over time.

The objective of this paper was to compare HIV prevalence, HIV risk taking and service use between U.S. born and foreign-born MSM living in San Francisco. We hypothesized based on the literature that foreign-born MSM would have less access to HIV-related services, potentially higher risk-taking behaviors and higher HIV prevalence; and that longer duration in San Francisco would result in higher risk-taking behaviors and HIV prevalence.

\section{METHODS}

\section{NATIONAL HIV BEHAVIORAL SURVEILLANCE SYSTEM}

This study used data from the National HIV Behavioral Surveillance System (NHBS) conducted in San Francisco in 2011. A description of the NHBS surveys and details of their methodology have been published (Gallagher, Sullivan, Lansky, \& Onorato, 2007). Briefly, NHBS-a project coordinated by the Centers for Disease Control and Prevention (CDC)—conducts a series of cross-sectional surveys aimed 
at understanding HIV-related behaviors, trends, and prevalence in 21 metropolitan statistical areas (MSA) across the United States, including the San Francisco Bay Area. The survey uses venue-based, time-space sampling methods to sample MSM frequenting venues presented in detail elsewhere (MacKellar et al., 2007).

Men were eligible to participate if they were 18 years or older, lived within the MSA, reported past male/male sexual behavior, able to provide verbal consent, and able to speak English or Spanish. Eligible participants completed a standardized interviewer-administered questionnaire covering demographics, sexual behaviors, HIV and STI test history, health coverage, and utilization of healthcare services. They were also offered an option to provide blood samples for HIV antibody testing, the results of which they could receive a week later in person or by telephone. Standard HIV antibody testing on serum samples collected by venipuncture was done at the San Francisco Public Health Laboratory. Initially reactive results were confirmed by standard laboratory methods.

The present study utilized anonymous secondary data from the NHBS and therefore did not require Institutional Review Board review. The parent NHBS studies received ethical approval from the University of California, San Francisco's Committee on Human Research. All participation was anonymous and as such no personal identifiers were collected at any point in the study.

\section{MEASURES}

Being a migrant was defined as being foreign born versus being born in the United States. We measured time lived in San Francisco with a continuous response variable "How many years have you live in San Francisco?" If participants responded less than a year the response was coded as 1 year or less. This measure was further dichotomized into a binary variable $(<5$ years and $>5$ years). Other predictors of interest included age, education, income, and sexual identity.

In terms of race, if men responded to being Latino/Hispanic (Are you Latino or Hispanic?), they were categorized as Latino regardless of their racial identification. The other participants were categorized into Black, White, Asian, or other according to their self-identifications. The other group includes Hawaiian or Pacific Islanders, Native Americans, and mixe-race individuals. Those identifying as straight were grouped together with those identifying as bisexual straight men comprised only $0.6 \%(n=3)$ of the aggregate population.

The outcome variables tested included prevalent HIV infection, unprotected anal intercourse in the past six months (includes both receptive and insertive acts), recent HIV testing in the past six months (among those who did not report being HIV positive as HIV-positive men are not expected to test for HIV regularly), recent STD testing in the past twelve months, current health insurance or health coverage, and recent visit to a healthcare provider in the past twelve months. In this analysis, reported unprotected anal intercourse (UAI) acts were limited to the last five sexual partners in the last six months. This partner specific assessment collects detailed sexual behaviors on a majority of participant's entire sexual history in the past six months. We calculated prevalent HIV infection using the results of the serological tests. Unrecognized HIV infection was defined as anyone NOT self-reporting being HIV positive and subsequently tested HIV positive in the study. For our analyses, binary indicators for HIV status, UAI, and recent HIV or STD testing were constructed. Therefore, indeterminate responses such as "I don't know" and those missing were excluded from the analyses. 


\begin{abstract}
ANALYSES
We assessed differences in demographic characteristics between foreign-born MSM and those born in the United States by conducting $\chi^{2}$ tests (all demographic characteristics were categorical variables). We also conducted bivariate and multivariate logistic regression analyses to estimate the associations between demographic characteristics and binary outcome variables associated with HIV risk, and health care service utilization. Each multivariable model included age, race, education, sexual identity, location of birth, and time lived in San Francisco as predictor variables. In the multivariate model of prevalent HIV infections, sexual identity was omitted as there were only three HIV infections among bisexual/straight men. We also tested an interaction between being foreign born (yes/no) and time living in San Francisco ( 5 years or less/more than 5 years). We also tested an interaction between nativity (U.S. versus foreign birth) and time spent in San Francisco (5 years or less versus more than 5 years). The interaction was not significant in the multivariable model, therefore it is not presented in tables; however, results are available upon request. All tests and confidence intervals are two-sided and based on the $5 \%$ level of significance. We analyzed all data using STATA version 9 (College Station, TX). Estimates are unweighted, consistent with national NHBS analyses (Gallagher et al., 2007; MacKellar et al., 2007).
\end{abstract}

\title{
RESULTS
}

A total of 1,007 men were intercepted at 45 randomly selected venues during 103 recruitment events conducted over six months in 2011, with $63.0 \%(n=634)$ determined eligible. Of the eligible men, $80.4 \%(n=510)$ agreed to participate and were consented, enrolled, interviewed, HIV tested, and identified as MSM by selfreported behavior or sexual identity.

Overall, $47.6 \%$ were between 31 and 50 years old, and $58.9 \%$ identified as being White (Table 1). Most (85.4\%) had completed at least some college, and $49.2 \%$ were employed full-time, with $26.5 \%$ earning $\geq \$ 75,000$ per annum. The vast majority $(90.5 \%)$ identified as gay.

Overall, $20.7 \%(n=87)$ of the MSM were foreign-born. There were significant differences between foreign-born and U.S.-born MSM in San Francisco. Foreignborn MSM were younger, with more U.S.-born MSM aged 51 or over, than foreignborn MSM $\left(22.6 \%\right.$ vs. $8 \%$, respectively, $\left.\chi^{2}=9.47, p=0.009\right)$. Compared to the U.S.-born, more foreign-born MSM identified as Asian $(3.3 \%$ vs. $26.4 \%$, respectively, $\left.\chi^{2}=75.5, p<0.001\right)$ and Latino $\left(17.7 \%\right.$ vs. $28.7 \%$, respectively, $\chi^{2}=75.5$, $p<0.001)$. There were no differences between the two subpopulations in terms of educational attainment, employment status, annual household income, and sexual identity; $55.4 \%$ of U.S.-born and $64.4 \%$ of foreign-born MSM had college or higher degrees, and $27.5 \%$ of U.S.-born and $22.1 \%$ of foreign-born MSM earned an annual income $\geq \$ 75,000$ (Table 1 ).

Overall, $42.7 \%$ and $56.7 \%$ of participants had lived in San Francisco for five years or less and over five years, respectively. The same pattern held true among U.S.-born and foreign-born MSM. In terms of HIV infection, overall $78.8 \%$ were HIV negative, $19.2 \%$ were HIV positive and knew that they were infected, and $1.6 \%$ were HIV positive and did not know they were infected. Fewer foreign-born MSM were HIV infected (whether known or unrecognized infections) but the difference compared to U.S.-born MSM was not significant (Table 1). An effect modifier 
TABLE 1. Demographic Characteristics of Men Who Have Sex With Men by U.S. vs. Foreign Birth, San Francisco, $2011(N=510)$

\begin{tabular}{|c|c|c|c|c|c|c|c|c|}
\hline \multirow[b]{2}{*}{ Characteristic } & \multicolumn{2}{|c|}{$\begin{array}{c}\text { Total } \\
(n=510)\end{array}$} & \multicolumn{2}{|c|}{$\begin{array}{l}\text { U.S. born } \\
(n=421)\end{array}$} & \multicolumn{2}{|c|}{$\begin{array}{l}\text { Foreign born } \\
\qquad(n=87)\end{array}$} & \multirow[b]{2}{*}{$\chi^{2}$} & \multirow[b]{2}{*}{$p$-value } \\
\hline & $n$ & $\%$ & $n$ & $\%$ & $n$ & $\%$ & & \\
\hline Age group, years & & & & & & & 9.47 & 0.009 \\
\hline $18-30$ & 164 & 32.3 & 132 & 31.4 & 32 & 36.8 & & \\
\hline $31-50$ & 242 & 47.6 & 194 & 46.1 & 48 & 55.2 & & \\
\hline$\geq 51$ & 102 & 20.1 & 95 & 22.6 & 7 & 8 & & \\
\hline Race/ethnicity & & & & & & & 75.5 & $<0.001$ \\
\hline White & 298 & 58.9 & 270 & 64.4 & 28 & 32.2 & & \\
\hline Asian & 37 & 7.3 & 14 & 3.3 & 23 & 26.4 & & \\
\hline Black & 31 & 6.1 & 30 & 7.2 & 1 & 1.1 & & \\
\hline Latino & 99 & 19.6 & 74 & 17.7 & 25 & 28.7 & & \\
\hline Other & 41 & 8.1 & 31 & 7.4 & 10 & 11.5 & & \\
\hline Education & & & & & & & 3.45 & 0.327 \\
\hline$\leq$ High school & 74 & 14.6 & 66 & 15.7 & 8 & 9.2 & & \\
\hline Some college & 145 & 28.5 & 122 & 29 & 23 & 26.4 & & \\
\hline College & 179 & 35.2 & 143 & 34 & 36 & 41.4 & & \\
\hline Postgraduate & 110 & 21.7 & 90 & 21.4 & 20 & 23 & & \\
\hline Employment & & & & & & & 5.7 & 0.127 \\
\hline Full-time & 250 & 49.2 & 200 & 47.5 & 50 & 57.5 & & \\
\hline Part-time & 90 & 17.7 & 78 & 18.5 & 12 & 13.8 & & \\
\hline Unemployed & 74 & 14.6 & 67 & 15.9 & 7 & 8 & & \\
\hline Other & 94 & 18.5 & 76 & 18.1 & 18 & 20.7 & & \\
\hline Annual Household Income, USD & & & & & & & 1.09 & 0.579 \\
\hline$\leq 29,999$ & 183 & 36.5 & 149 & 35.9 & 34 & 39.5 & & \\
\hline $30,000-74,999$ & 185 & 36.9 & 152 & 36.6 & 33 & 38.4 & & \\
\hline$\geq 75,000$ & 133 & 26.5 & 114 & 27.5 & 19 & 22.1 & & \\
\hline Sexual Identity & & & & & & & 1.6 & 0.212 \\
\hline Gay & 457 & 90.5 & 377 & 89.8 & 80 & 94.1 & & \\
\hline Bisexual or Straight & 48 & 9.5 & 43 & 10.2 & 5 & 5.9 & & \\
\hline Time in San Francisco & & & & & & & 0.00 & 1.0 \\
\hline$<=5$ years & 218 & 42.7 & 181 & 42.9 & 37 & 42.5 & & \\
\hline$>5$ years & 289 & 56.7 & 240 & 57.1 & 49 & 56.3 & & \\
\hline HIV status & & & & & & & 2.23 & 0.33 \\
\hline Known HIV infection & 98 & 19.2 & 86 & 20.4 & 12 & 13.8 & & \\
\hline Unrecognized HIV infection & 8 & 1.6 & 7 & 1.7 & 1 & 1.1 & & \\
\hline Not HIV infected & 402 & 78.8 & 328 & 77.9 & 74 & 85.1 & & \\
\hline
\end{tabular}

Note. Not all categories sum to $100 \%$ due to missing data.

testing foreign birth and duration of time in the U.S. was also included, but was nonsignificant (data not shown, but available upon request).

There were no significant differences between foreign-born and U.S.-born MSM in terms of unprotected anal intercourse in the past six months, recent HIV testing in the past six months, recent STI testing in the past twelve months, current health coverage and visit to a healthcare provider in the past year (Table 2).

Table 3 shows bivariate and multivariate associations with HIV infection. HIV infection was bivariately positively associated with ages $31-50$ (odds ratio [OR] 3.4, confidence interval [CI] [1.6, 6.2]) and 51 or older (OR 4.2, CI [2.1, 8.3]), and living in San Francisco for more than 5 years (OR 2.86, CI [1.98, 5.47]). HIV infection was negatively associated with earning more than $\$ 75,000$ per annum (OR 0.49, CI $[0.23,0.75])$, being a college graduate (OR 0.36, [CI 0.19, 0.68]), and having post graduate studies (OR 0.48, CI [0.25-0.95]). In multivariable analysis, HIV prevalence was positively correlated with being aged 31-50 years (AOR, 3.29; 95\% CI 
TABLE 2. Unprotected Anal Intercourse and Access to Health Care by U.S. vs. Foreign Birth, Men Who Have Sex With Men, San Francisco, 2011 ( N = 510)

\begin{tabular}{|c|c|c|c|c|c|c|c|c|}
\hline \multirow[b]{2}{*}{ Characteristic } & \multicolumn{2}{|c|}{$\begin{array}{c}\text { Total } * \\
(n=510)\end{array}$} & \multicolumn{2}{|c|}{$\begin{array}{l}\text { U.S. born } \\
(n=421)\end{array}$} & \multicolumn{2}{|c|}{$\begin{array}{l}\text { Foreign born } \\
\qquad(n=87)\end{array}$} & \multirow[b]{2}{*}{$\chi^{2}$} & \multirow[b]{2}{*}{$p$-value } \\
\hline & $n$ & $\%$ & $n$ & $\%$ & $n$ & $\%$ & & \\
\hline Unprotected anal intercourse & 238 & 46.9 & 194 & 46.1 & 44 & 50.6 & 0.58 & 0.444 \\
\hline Recent HIV testing, past 6 months & 246 & 48.4 & 204 & 48.5 & 42 & 48.3 & 0.0009 & 0.976 \\
\hline Recent STI testing, past 12 months & 293 & 58.4 & 243 & 58.4 & 50 & 58.1 & 0.0022 & 0.963 \\
\hline Currently have health insurance & 388 & 76.4 & 320 & 76.0 & 68 & 78.2 & 0.1850 & 0.667 \\
\hline $\begin{array}{l}\text { Visited healthcare provider, past } 12 \\
\text { months }\end{array}$ & 441 & 86.8 & 367 & 87.2 & 74 & 85.1 & 0.2819 & 0.595 \\
\hline
\end{tabular}

Note. *Percent for category based on nonmissing total.

$[1.64,6.62])$ and $>51$ years (AOR, 3.04; 95\% CI [1.31, 7.08]), and negatively correlated with having an annual income $\geq \$ 75,000$ (AOR, 0.31; 95\% CI $[0.16,0.60]$ ) and having a college degree (AOR, 0.35; 95\% CI [0.18, 0.71]). While foreign birth was not associated with HIV, time living in San Francisco was, with those living there more than 5 years having over twice the odds of infection (AOR, 1.89; 95\% CI $[1.06,3.35])$, even after controlling for age, income, and education. Of note, HIV prevalence was not associated with race/ethnicity in this survey of MSM in San Francisco in 2011.

\section{DISCUSSION}

Our analyses suggest that foreign-born MSM are not inherently at risk for HIV infection but that with increased duration of residency in San Francisco, there is a substantial and significantly increased odds of infection for all MSM. This finding held even after controlling for age. Consistent with other reports, HIV infection was higher among men in older age groups, with lower income, and lower education (Ayala et al., 2012; Wejnert et al., 2013).

In terms of migration, similar results have been observed in studies of MSM in South Florida and Latino MSM, where established migrants who have resided in the area for more than five years had higher HIV prevalence than their recent counterparts who had been present for less than one year (Egan et al., 2011; Oster et al., 2013). Qualitative interviews of Latino migrant MSM in New York City found that their new social environment allowed them some release from the structural homonegativity and social contexts of their home countries to explore greater sexual freedom in the anonymity and bounty of sexual partners in a gay epicenter such as New York City (Bianchi et al., 2007). These results are also in line with larger migration literature which suggests that newly arrived migrants are healthier compared to native populations and that this healthy migrant effect attenuates over time with the health of the migrant deteriorating over increasing time spent in the new place (McDonald \& Kennedy, 2004; Singh \& Siahpush, 2002). How this hypothesis might manifest, be it through acculturation stresses, adoption of American socio-cultural norms, unavailability of coping resources, or lack of social capital, is outside the scope of this study and a future avenue for research (Berry, 1997; Chng et al., 2003; Fennelly, 2007). 
TABLE 3. Correlates of HIV Infection, Men Who Have Sex With Men, San Francisco, $2011(N=510)$

\begin{tabular}{|c|c|c|c|c|c|c|c|c|}
\hline \multirow[b]{2}{*}{ Demographic characteristics } & \multicolumn{2}{|c|}{ HIV negative } & \multicolumn{2}{|c|}{ HIV positive $(N=106)$} & \multirow[b]{2}{*}{ OR } & \multirow[b]{2}{*}{$95 \% \mathrm{CI}$} & \multirow[b]{2}{*}{ AOR } & \multirow[b]{2}{*}{$95 \% \mathrm{CI}$} \\
\hline & $n$ & $\%$ & $n$ & $\%$ & & & & \\
\hline \multicolumn{9}{|l|}{ Age group, years } \\
\hline $18-30$ & 151 & 90.9 & 15 & 9.0 & & & & \\
\hline $31-50$ & 181 & 74.8 & 61 & 25.2 & $3.4 * * *$ & {$[1.6,6.2]$} & $3.29 * *$ & {$[1.64,6.62]$} \\
\hline$>51$ & 72 & 70.6 & 30 & 29.4 & $4.2 * * *$ & {$[2.1,8.3]$} & $3.04 * *$ & {$[1.31,7.08]$} \\
\hline \multicolumn{9}{|l|}{ Race/ethnicity } \\
\hline White & 228 & 46.0 & 72 & 24.0 & & & & \\
\hline Asian & 33 & 89.2 & 4 & 10.8 & 0.38 & {$[0.13,1.12]$} & 0.64 & {$[0.20,2.07]$} \\
\hline Black & 26 & 83.8 & 5 & 16.1 & 0.61 & {$[0.23,1.64]$} & 0.66 & {$[0.23,1.95]$} \\
\hline Latino & 89 & 83.8 & 16 & 16.2 & 0.61 & {$[0.34,1.11]$} & 0.69 & {$[0.36,1.35]$} \\
\hline Others & 34 & 79.1 & 9 & 20.9 & 0.78 & {$[0.39,1.54]$} & 0.74 & {$[0.32,1.70]$} \\
\hline \multicolumn{9}{|c|}{ Annual Household Income, USD } \\
\hline$<=29,999$ & 137 & 74.1 & 48 & 25.9 & & & & \\
\hline $30,000-74,999$ & 144 & 77.8 & 41 & 22.2 & 0.81 & {$[0.53,1.36]$} & 0.80 & {$[0.48,1.37]$} \\
\hline$>=75,000$ & 129 & 87.9 & 17 & 12.1 & $0.49 * *$ & {$[0.23,0.75]$} & $0.31 \% *$ & {$[0.16,0.60]$} \\
\hline \multicolumn{9}{|l|}{ Education } \\
\hline High school or less & 51 & 67.1 & 25 & 32.9 & & & & \\
\hline Some college & 11 & 77.2 & 33 & 22.8 & 0.60 & {$[0.33,1.11]$} & 0.53 & {$[0.27,1.03]$} \\
\hline College graduate & 152 & 84.9 & 27 & 16.1 & $0.36 * *$ & {$[0.19,0.68]$} & $0.35 \% *$ & {$[0.18,0.71]$} \\
\hline Postgraduate & 89 & 80.9 & 21 & 19.1 & $0.48^{*}$ & {$[0.25,0.95]$} & 0.47 & {$[0.22,1.04]$} \\
\hline \multicolumn{9}{|l|}{ Location of birth } \\
\hline U.S.-born & 328 & 77.9 & 93 & 22.1 & & & & \\
\hline Foreign-born & 74 & 85.1 & 13 & 14.9 & 0.62 & {$[0.33,1.17]$} & 0.73 & {$[0.36,1.49]$} \\
\hline \multicolumn{9}{|l|}{$\begin{array}{l}\text { Time lived in San Francisco, } \\
\text { years }\end{array}$} \\
\hline$<=5$ & 194 & 88.2 & 26 & 11.8 & & & & \\
\hline$>5$ & 209 & 72.3 & 87 & 27.7 & $2.86 * * *$ & {$[1.98,5.47]$} & $1.89 \%$ & {$[1.06,3.35]$} \\
\hline
\end{tabular}

Note. Percent for total nonmissing data. ${ }^{*} p<0.05$. ${ }^{* *} p<0.01$. $* * * p<0.001$.

Nonetheless, we hypothesize that increased duration of residency may imply an accumulated risk or higher HIV-transmission probabilities due to the high background prevalence of HIV in San Francisco coupled with on-going if not higher levels of risk behavior, especially if proper prevention methods are not employed (Lasry et al., 2014). Our findings of HIV associated with lower income, lower education, and time in San Francisco suggest the need for interventions that focus on the potentially disadvantaged lower socioeconomic status MSM regardless of whether they are foreign-born or U.S.-born.

Our study also found that there were no differences in health insurance or coverage at the time of the survey between foreign-born and U.S.-born MSM. This is in stark contrast from the general migrant where discrepancies in healthcare coverage have been observed when comparing U.S.-born, documented and undocumented immigrants in California (Pourat, Wallace, Hadler, \& Ponce, 2014). This might be explained by the demographic differences—or lack thereof-observed between U.S.born and foreign-born MSM populations from our analyses, where we observed no differences in terms of income, education, sexual identity, and duration of residency 
in San Francisco between the two groups although the NHBS does not collect information regarding immigration status. Whether this holds in cities other than San Francisco where social norms may differ significantly should be further examined.

The analysis presented here is subject to several limitations. First, the cross-sectional nature of the NHBS does not allow for directly assessing when infection occurred. Therefore, it is not possible to determine causal associations between nativity, and HIV prevalence and behaviors. The study did ask about timing of migration; however, and this study attempts to capture timing and duration in San Francisco. Second, the small sample size limits stratified analyses to analyze HIV prevalence and risk behaviors by race/ethnicity of the migrant. Third, this study presents data from the San Francisco/Bay Area. Further analyses should be explored in other cities, with varying degrees of foreign-born and different social milieu to assess how context may influence these relationships. Lastly, our behavioral measures are all self-reported and therefore, may be subject to reporting and recall biases.

Despite these limitations, our study suggests that further investigation into different migrant communities in other geographic locations within the United States is warranted. San Francisco represents a unique location, and understanding community level influences such as levels of stigma, discrimination, and health services may modify the relationships that we found between time in residence and incidence of HIV. Migrant MSM are also a heterogeneous group thus we need to better understand subpopulations of migrants. Moreover, framing further investigations in terms of transnational experiences could provide insights into how originating locations shape sexual attitudes that may carry over to behaviors in receiving locations. Finally, our analysis contributes to a better understanding of HIV infection among migrant MSM and suggests more effective ways of potentiating HIV prevention strategies for all MSM in San Francisco and possibly elsewhere.

\section{REFERENCES}

Ayala, G., Bingham, T., Kim, J., Wheeler, D. P., \& Millett, G. A. (2012). Modeling the impact of social discrimination and financial hardship on the sexual risk of HIV among Latino and Black men who have sex with men. American Journal of Public Health, 102, S242-249. doi:10.2105/ AJPH.2011.300641

Berry, J. W. (1997). Immigration, acculturation, and adaptation. Applied Psychology, 46, $5-34$.

Bianchi, F. T., Reisen, C. A., Zea, M. C., Poppen, P. J., Shedlin, M. G., \& Penha, M. M. (2007). The sexual experiences of Latino men who have sex with men who migrated to a gay epicentre in the USA. Culture, Health and Sexuality, 9, 505-518. doi:10.1080/13691050701243547

Carrillo, H. (2004). Sexual migration, cross-cultural sexual encounters, and sexual health. Sexuality Research \& Social Policy, 1, 58-70.

Chauncey, G. (1994). Gay New York: The making of the gay male world, 1890-1940. London: Flamingo.
Chng, C. L., Wong, F. Y., Park, R. J., Edberg, M. C., \& Lai, D. S. (2003). A model for understanding sexual health among Asian American/Pacific Islander men who have sex with men (MSM) in the United States. AIDS Education and Prevention, 15, 21-38.

Decosas, J., \& Adrien, A. (1997). Migration and HIV. AIDS, 11, S77-S84.

Díaz, R. M., Ayala, G., \& Bein, E. (2004). Sexual risk as an outcome of social oppression: Data from a probability sample of Latino gay men in three U.S. cities. Cultural Diversity and Ethnic Minority Psychology, 10, 255-267. doi:10.1037/10999809.10.3.255

Egan, J. E., Frye, V., Kurtz, S. P., Latkin, C., Chen, M., Tobin, K., ... Koblin, B. A. (2011). Migration, neighborhoods, and networks: Approaches to understanding how urban environmental conditions affect syndemic adverse health outcomes among gay, bisexual and other men who have sex with men. AIDS and Behavior, 15(Suppl 1), S35-S50.

Fennelly, K. (2007). The "healthy migrant" effect. Minnesota Medicine, 90, 51-53. 
Frye, V., Latka, M. H., Koblin, B., Halkitis, P. N., Putnam, S., Galea, S., \& Vlahov, D. (2006). The urban environment and sexual risk behavior among men who have sex with men. Journal of Urban Health, 83, 308-324. doi:10.1007/s11524-006-9033-x

Gallagher, K. M., Sullivan, P. S., Lansky, A., \& Onorato, I. M. (2007). Behavioral surveillance among people at risk for HIV infection in the U.S.: the National HIV Behavioral Surveillance System. Public Health Reports, 122, S32-S38.

Huang, F. Y., \& Akhtar, S. (2005). Immigrant sex: The transport of affection and sensuality across cultures. American Journal of Psychoanalysis, 65, 179-188. doi:10.1007/ s11231-005-3625-1

Jarama, S. L., Kennamer, J. D., Poppen, P. J., Hendricks, M., \& Bradford, J. (2005). Psychosocial, behavioral, and cultural predictors of sexual risk for HIV infection among Latino men who have sex with men. AIDS and Behavior, 9, 513-523. doi:10.1007/ s10461-005-9022-1

Kalichman, S. C., Weinhardt, L., DiFonzo, K., Austin, J., \& Luke, W. (2002). Sensation seeking and alcohol use as markers of sexual transmission risk behavior in HIV-positive men. Annals of Behavioral Medicine, 24, 229-235.

Kane, F., Alary, M., Ndoye, I., Coll, A. M., M’boup, S., Guèye, A., .. . Joly, J. R. (1993). Temporary expatriation is related to HIV-1 infection in rural Senegal. AIDS, 7, 1261-1265.

Lasry, A., Sansom, S. L., Wolitski, R. J., Green, T. A., Borkowf, C. B., Patel, P., \& Mermin, J. (2014). HIV sexual transmission risk among serodiscordant couples: Assessing the effects of combining prevention strategies. AIDS, 28, 1521-1529. doi:10.1097/ QAD.0000000000000307

MacKellar, D. A., Gallagher, K. M., Finlayson, T., Sanchez, T., Lansky, A., \& Sullivan, P. S. (2007). Surveillance of HIV risk and prevention behaviors of men who have sex with men-A national application of venuebased, time-space sampling. Public Health Reports, 122, 39-47.

McDonald, J. T., \& Kennedy, S. (2004). Insights into the 'healthy immigrant effect': Health status and health service use of immigrants to Canada. Social Science and Medicine, 59, 1613-1627. doi:10.1016/j.socscimed.2004.02.004

Nunn, A. J., Wagner, H. U., Kamali, A., KengeyaKayondo, J. F., \& Mulder, D. W. (1995). Migration and HIV-1 seroprevalence in a rural Ugandan population. AIDS, 9, 503506.
Oster, A. M., Russell, K., Wiegand, R. E., Valverde, E., Forrest, D. W., Cribbin, M., .. . NBHS Study Group. (2013). HIV infection and testing among Latino men who have sex with men in the United States: The role of location of birth and other social determinants. PLoS One, 8, e73779. doi:10.1371/ journal.pone.0073779

Pourat, N., Wallace, S. P., Hadler, M. W., \& Ponce, N. (2014). Assessing health care services used by California's undocumented immigrant population in 2010. Health Affairs (Millwood), 33, 840-847. doi:10.1377/ hlthaff.2013.0615

Raymond, H. F., Chen, Y.-H., Ick, T. O., Scheer, S., Bernstein, K., Liska, S., . . . McFarland, W. (2013). A new trend in the HIV epidemic among men who have sex with men, San Francisco, 2004-2011. Journal of Acquired Immune Deficiency Syndromes, 62, 584589. doi:10.1097/QAI.0b013e318285febf.

San Francisco Department of Public Health. (2011). HIV/AIDS Epidemiology Annual Report. Retrieved July 27, 2014, from http://www.sfdph.org/dph/files/reports/default.asp

Sanchez, M. A., Lemp, G. F., Magis-Rodríguez, C., Bravo-García, E., Carter, S., \& Ruiz, J. D. (2004). The epidemiology of HIV among Mexican migrants and recent immigrants in California and Mexico. Journal of Acquired Immune Deficiency Syndromes, 37, S204-S214.

Singh, G. K., \& Siahpush, M. (2002). Ethnic-immigrant differentials in health behaviors, morbidity, and cause-specific mortality in the United States: An analysis of two national data bases. Human Biology, 74, 83-109.

Smith, D. M., \& Gates, G. J. (2001). Gay and Lesbian families in the United States: Same-sex unmarried partner households. A preliminary analysis of 2000 United States Census data. Retrieved from http://www.urban.org/ UploadedPDF/1000491_gl_partner_households.pdf website

Tsui, H. Y., \& Lau, J. T. (2010). Comparison of risk behaviors and socio-cultural profile of men who have sex with men survey respondents recruited via venues and the internet. $B M C$ Public Health, 10, 232. doi:10.1186/14712458-10-232

Wejnert, C., Le, B., Rose, C. E., Oster, A. M., Smith, A. J., Zhu, J., \& Paz-Bailey, G. (2013). HIV infection and awareness among men who have sex with men-20 cities, United States, 2008 and 2011. PLoS One, 8, e76878. doi:10.1371/journal.pone.0076878 